\title{
Ultrasonic-Assisted Dispersion of Zn0 Nanoparticles to Sn-Bi Solder: A Study on Microstructure, Spreading, and Mechanical Properties
}

\author{
Sri Harini Rajendran, Hyejun Kang, and Jae Pil Jung
}

\author{
Submitted: 26 September 2020 / Revised: 1 December 2020 / Accepted: 21 January 2021 / Published online: 10 February 2021
}

\begin{abstract}
Nanocomposite Sn-Bi solders received noticeable attention for flexible electronics due to their improved mechanical properties. The main limitation is the dispersion of nanoparticles in the solder alloy. Accordingly, in this work, varying additions of $\mathrm{ZnO}$ nanoparticles were successfully dispersed into $\mathrm{Sn} 57 \mathrm{Bi}$ solder via the liquid-state ultrasonic treatment. Nanocomposite solders were prepared using the melting and casting route. The solder alloys were then characterized for microstructure, spreading and mechanical properties. With increasing $\mathrm{ZnO}$ addition, the microstructure revealed significant refinement of $\mathrm{Bi}$ - and $\mathrm{Sn}$ rich phases. Consequently, the eutectic lamellar spacing also decreases. The spreading improved up to 0.1 wt.\% ZnO addition. For higher additions, nanocomposite solders experienced deterioration in spreading characteristics. The tensile strength of the solder increases with an increase in the amount of $\mathrm{ZnO}$ nanoparticles. High ductility is achieved for nanocomposite solder containing $0.05 \mathrm{wt} . \% \mathrm{ZnO}$. An attempt was made, to explain the effect of increasing $\mathrm{ZnO}$ nanoparticle addition on microstructural, spreading, and mechanical properties of Sn57Bi solder.
\end{abstract}

Keywords Sn-Bi solder, spreading, tensile test, ultrasonic treatment

\section{Introduction}

Flexible and wearable devices have become a forefront topic in the research and development of the electronic industry. However, integration of functional components such as semiconductors and inorganic chips remains a barrier in achieving the robustness of the flexible electronic device (FET) (Ref 1). Presently, conductive adhesives are utilized as an interconnect material for flexible electronics. Conductive adhesives have poor electrical conductivity and impact strength at high operating temperatures (Ref 1,2). Research toward establishing solder materials for high power FET's are highly focused, in particular, eutectic $\mathrm{Sn}-\mathrm{Bi}$ solders capture the growing interest due to their cost effectiveness and melting temperature $\left(139^{\circ} \mathrm{C}\right)($ Ref $2-7)$. Meanwhile, brittleness of Bi phase intermetallic compounds (IMC) accounts to a reliability concern since FET's may experience mechanical shock upon bending (Ref 1). Addition of NPs in Sn-Bi solder alloy is an efficient

This article is an invited paper selected from abstracts submitted to the 5th International Conference on Nanojoining and Microjoining (NMJ 2020), that was to be held from September 20-23, 2020, in Leipzig, Germany. The conference was postponed due to the coronavirus (COVID-19) pandemic. The paper has been expanded from the planned presentation.

Sri Harini Rajendran, Hyejun Kang, and Jae Pil Jung, Department of Materials Science and Engineering, University of Seoul, 163 Seoulsiripdaero, Dongdaemun-gu, Seoul 02504, Republic of Korea. Contact e-mails: harini.phys@gmail.com and jpjung@uos.ac.kr. way to improve the reliability of the solder joints by reducing the IMC thickness as well as refining the brittle Bi phase (Ref 3). NPs also enhance wettability (Ref 5), electro-migration performance (Ref 6), corrosion resistance (Ref 7) and reduce the coarsening of Bi phase upon aging (Ref 4). Wu et al. (Ref 8) reported the addition of $1 \mathrm{wt} . \% \mathrm{ZnO} \mathrm{NPs}$, substantially reduced the $\mathrm{Cu}-\mathrm{Ni}-\mathrm{Sn}$ thickness at the interface and increased the shear strength of Sn-57.6Bi-0.4Ag solder joints on Ni metallized $\mathrm{Cu}$ pads. However, the result of $\mathrm{ZnO}$ NPs addition on the wetting characteristics and the tensile property of Sn-Bi solder alloy has not be studied. Besides, dispersion of ceramic NPs in the molten solder is a challenging task due to the poor wetting between ceramic NPs and the molten metal. NPs are generally expelled from the molten solder during the fabrication (Ref 9). Further, nanoparticles tend to agglomerate due to their high surface energy and hence may retard the dispersion during conventional mixing techniques such as stir casting and mechanical solder paste mixing. Hence, advanced mixing techniques must be adapted to successfully disperse the nanoparticles in the solder alloy.

Ultrasonic treatment (UT) of molten metal has been reported by many researchers as one of the effective methods to disperse the NPs in $\mathrm{Al}$ and $\mathrm{Mg}$ alloys (Ref 10). The shock waves generated from the acoustic bubble collapse can de-agglomerate the NPs during dispersion (Ref 9, 11). Additionally, it is reported that sono-capillary effect by acoustic cavitation can enhance the wettability of molten metals on ceramic surface (Ref 11-13). Tzanakis et al. (Ref 13) confirmed the sonocapillary effect through the penetration of molten aluminum on the pre-existing oxide groove in the presence of UT. The benefits of UT are utilized in various metal processing techniques such as dispersion of NPs (Ref 9), infiltration (Ref 11) and alloy refinement (Ref 12). However, dispersion of nanoparticles in the molten solder by UT is yet to be achieved. Therefore, in the present work, ZnO NPs are dispersed in Sn-Bi solder using UT and the influence of $\mathrm{ZnO}$ on the microstruc- 
ture, spreading and mechanical properties of Sn57Bi solder are discussed.

\section{Experimental Procedure}

Sn57Bi solder ingot of purity $99.9 \%$ acquired from BNF, South Korea and $\mathrm{ZnO}$ nanoparticles (NPs) of purity $99.5 \%$ and an average individual particle size of $15-25 \mathrm{~nm}$ purchased from Ditto Technology, South Korea were used as starting materials. Figure 1(a) shows the field emission scanning electron microscope image and EDS analysis of as purchased $\mathrm{ZnO}$ nanopowders. The average aggregate (sintered individual particles) size of as-purchased $\mathrm{ZnO}$ powders were found to be $53 \pm 10 \mathrm{~nm}$. Series of Sn57Bi- $x \mathrm{ZnO}(x=0.05,0.1,0.2$ and 0.4 wt. $\%$ ) nanocomposite solders were prepared by melting and casting method. The $\mathrm{Sn}-\mathrm{Bi}$ solder was heated to $400{ }^{\circ} \mathrm{C}$ in a melting furnace and accurately weighted $\mathrm{ZnO}$ NPs in pellet form was incorporated in the molten solder in the presence of UT. Piezoelectric ultrasonic transducer (Hangzhou Dowell Ultrasonic Technology, Co. Ltd, China) coupled with SS304 sonotrode with diameter of $3 \mathrm{~cm}$, frequency of $20 \mathrm{kHz}$ and $70 \%$ amplitude was used for dispersing the NPs. The molten solder was subjected to an UT for $3 \mathrm{~min}$ and cast on a stainless steel mold. During melting and casting, Ar gas was flowed continuously on the surface of the molten solder to prevent the oxidation. Microstructure samples were mounted in an epoxy resin, polished and etched with a solution containing 3 vol. $\% \mathrm{HCl}, 5$ vol. $\% \mathrm{HNO}_{3}$ and 92 vol. $\% \mathrm{CH}_{3} \mathrm{OH}$. The microstructure of the nanocomposite solder alloys was analyzed using analytical scanning electron microscope (SEM) (JEOL JSM-6010PLUS, Tokyo, Japan) attached with energy dispersive spectrometer (EDS). The eutectic spacing was measured using Image-Pro Plus 6.0 program.

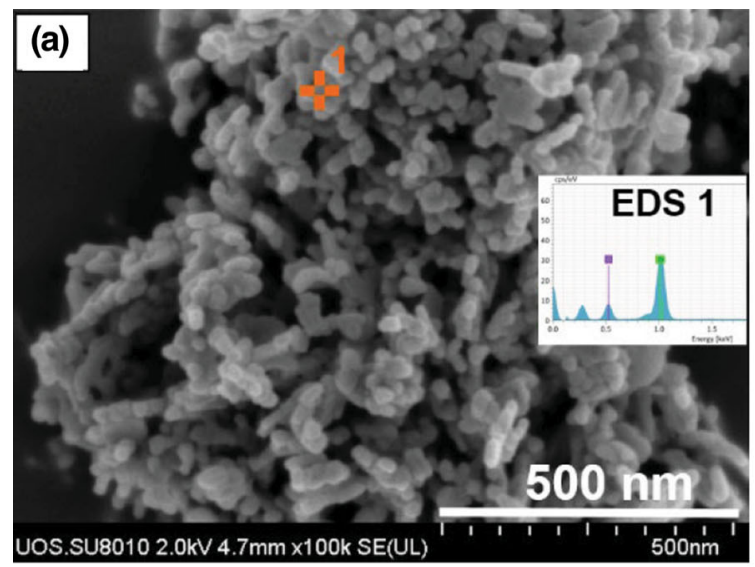

The spreading ratio $(S)$ of solder bump is calculated in accordance with Japanese Industrial Standard (JIS-Z-3197) (Ref 12):

$S=\left(\frac{D-H}{D}\right) \times 100$

$D$ is the diameter of the solder spread (assumed to be a sphere); $D=1.24 V^{1 / 3} ; V$ is the mass/specific gravity of the solder alloy; $H$ is the height of the solder after spreading. $99.99 \%$ pure copper test substrate $(30 \mathrm{~mm} \times 30 \mathrm{~mm} \times 0.3 \mathrm{~mm})$ and $0.3 \mathrm{~g}$ of near-spherical as prepared solder were used for the spreading test in the presence of rosin mildly activated (RMA) flux. Spreading test was conducted at a peak temperature of $165^{\circ} \mathrm{C}$ for $60 \mathrm{~s}$. After cooling, the samples were cross sectioned to measure the spreading height $(H)$. Mechanical property of $\mathrm{ZnO}$ added Sn-58Bi solders were characterized through AUTOTENFORCE M/C (Korea-tech) tensile testing machine. Tensile tests were performed in room temperature at a fixed rate of $3.0 \mathrm{~mm} / \mathrm{min}$. Tensile tests were conducted in accordance with ASTM: E8 standard. The dimensions of tensile test sample was given in Figure 1(c). For each condition, five samples were tested and the average values were reported.

\section{Results and Discussion}

\subsection{Microstructure}

Figure 2 displays the microstructure and the eutectic spacing of monolithic and $\mathrm{ZnO}$ NPs added Sn57Bi solder. Figure 2(a) and (b) shows the microstructure of monolithic Sn57Bi solder and the elemental mapping of $\mathrm{Sn}$ and $\mathrm{Bi}$. Sn57Bi solder solidifies with a eutectic microstructure consisting of alternate Bi-rich (bright contrast) and Sn-rich phase (dark contrast) resulting in the lamellar structure as seen from Fig. 2(b).
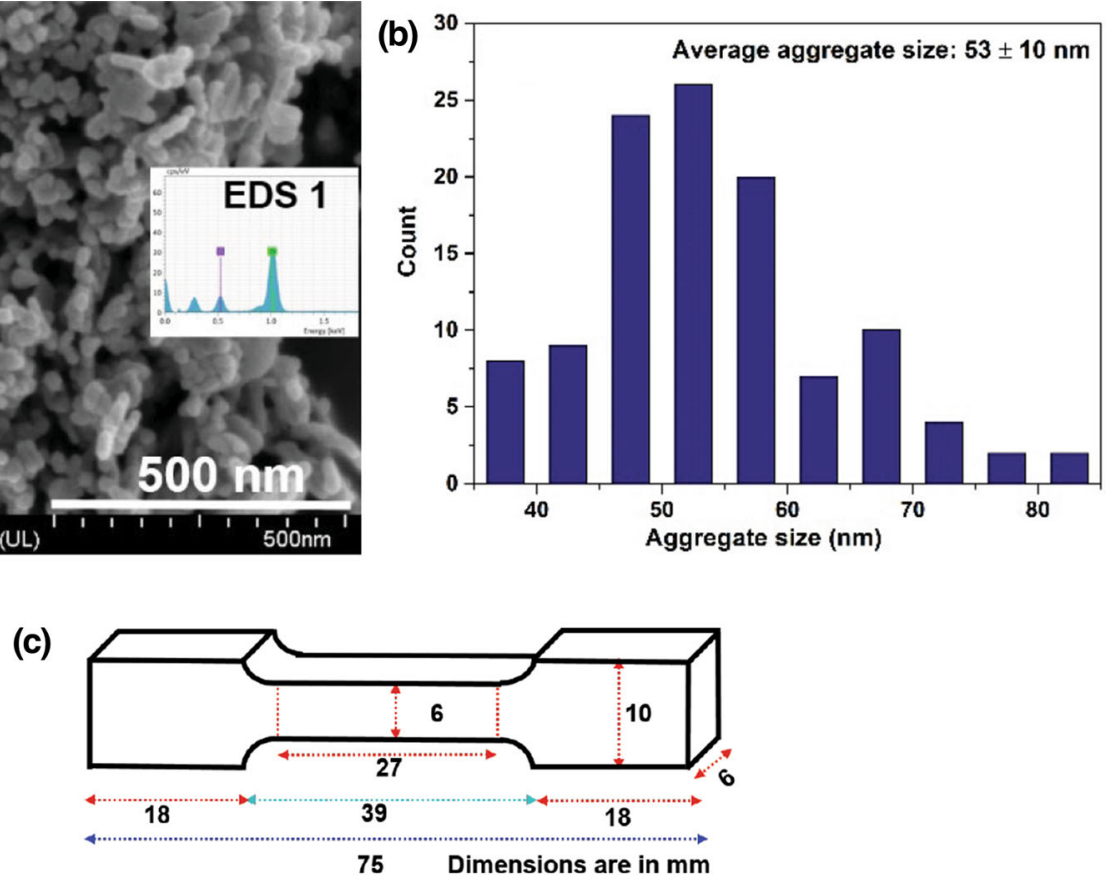

Figure 1 (a) FESEM image of as purchased $\mathrm{ZnO}$ nanoparticles with EDS analysis, (b) aggregate size distribution of as-purchased $\mathrm{ZnO}$ and (c) tensile sample dimensions 

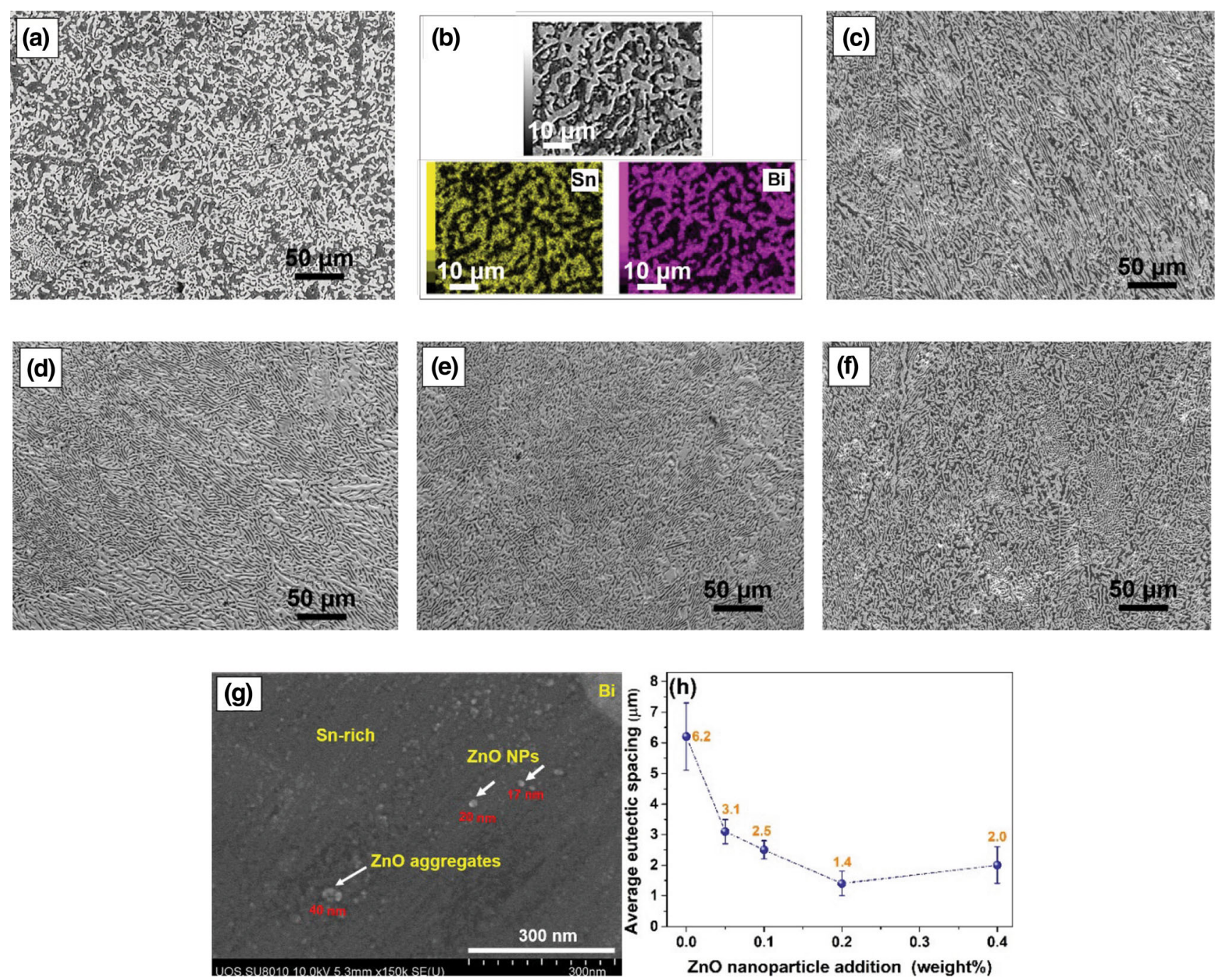

Figure 2 SEM image of (a) monolithic Sn57Bi, (b) high magnification elemental mapping of (a), (c) Sn57Bi-0.05 wt.\%ZnO, (d) Sn57Bi0.1 wt.\%ZnO, (e) Sn57Bi-0.2 wt.\%ZnO, (f) Sn57Bi-0.4 wt.\%ZnO, (g) ZnO aggregates dispersed in Sn57Bi-0.4 wt.\%ZnO alloy and (h) average eutectic spacing of $\mathrm{Sn} 57 \mathrm{Bi}$ solder with varying $\mathrm{ZnO}$ addition

Figure 2(c)-(f) shows the microstructure of $\mathrm{ZnO}$ NPs added Sn57Bi solder. The alternating Bi and Sn-rich eutectic morphology changes from coarse to a fine lamellar structure with the increasing addition of $\mathrm{ZnO}$ NPs up to $0.2 \mathrm{wt} \%$. The refinement has resulted in the significant reduction in the average eutectic spacing between $\mathrm{Sn}$-rich and $\mathrm{Bi}$ phase. However, as seen from Fig. 2(f), increasing the NPs addition to $0.4 \mathrm{wt} . \%$, tends to coarsen the eutectic lamellar structure. Figure $2(\mathrm{~g})$ shows the average eutectic lamellar spacing in monolithic and $\mathrm{ZnO}$ added $\mathrm{Sn} 57 \mathrm{Bi}$ solder. Eutectic lamellar spacing was measured using the linear intercept method from ten high magnification microstructures. The average eutectic lamellar spacing reduces with the addition of $\mathrm{ZnO}$, reaches a minimum value of $1.4 \pm 0.5 \mu \mathrm{m}$ for $0.2 \mathrm{wt} . \%$ addition and thereafter increases for the higher addition amount. However, the extent of coarsening is insignificant compared with the monolithic alloy.

Microstructural refinement can be attributed to $\mathrm{ZnO}$ NPs acting as active nucleation sites in the solder melt during solidification. Nucleation sites in the melt reduce the free energy barrier and promote the nucleation events during solidification (Ref 12). Additives acting as a potent nucleation site in $\mathrm{Sn}-\mathrm{Bi}$ solder have been previously reported for the addition of graphite NPs (Ref 15), Mo NPs (Ref 4) and $\mathrm{BaTiO}_{3}$ NPs (Ref 5). The effectiveness of an additive in enhancing the nucleation event depends on the contact angle established between the additive and the nucleating phase.

The nucleation free energy can be reduced by lowering the contact angle between the nucleation site and molten metal (Ref 12). Ceramics generally have poor wetting with the molten metal. However, UT can enhance the wetting of ZnO NPs through sono-capillary effect caused by acoustic cavitation (Ref 16). During UT, the trapped gases on the solid surface generate tiny bubbles due to the large flow rates and high pressure gradients. With acoustic pressure, the cavitation bubbles grow and finally collapse creating shock waves and molten liquid impinging on the solid surface. Micro-jetting from the shock wave improves the capillarity of molten $\mathrm{SnBi}$ liquid on $\mathrm{ZnO}$ NPs surface thereby enhancing their wettability (Ref 12, 13). $\mathrm{ZnO}$ NPs in molten liquid can exist as individual particles or in the form of aggregates and agglomerates. The shock waves can disrupt the $\mathrm{ZnO} \mathrm{NP}$ agglomerates and the acoustic streaming generated upon UT can disperse the $\mathrm{ZnO} \mathrm{NP}$ aggregates in the molten alloy (Ref 12). In this way, UT can synergistically 
enhance the wetting as well as the dispersion of $\mathrm{ZnO}$ NPs in the solder matrix. Figure 2(g) shows the $\mathrm{ZnO}$ aggregates and individual particles dispersed in the $\mathrm{Sn} 57 \mathrm{Bi}$ alloy matrix. At higher addition amount, the increased NPs interactions can lead to clustering of $\mathrm{ZnO}$ NPs. These clusters can be pushed during the dendritic growth presumably reducing the number of $\mathrm{ZnO}$ nucleation sites resulting in the coarsening of $\mathrm{Bi}$ and $\mathrm{Sn}$-rich phases.

\subsection{Spreading Ratio}

The higher spreading ratio reflects a good wettability of the solder and is considered as one of the most desirable properties for soldering. Figure 3(a) shows the spreading ratio for monolithic and $\mathrm{ZnO}$ NPs added Sn57Bi solders on the $\mathrm{Cu}$ substrate. The average spreading rate of monolithic Sn-57Bi solder on the $\mathrm{Cu}$ substrate is $70.7 \%$. With the addition of 0.05 and 0.1 wt. $\%$ of $\mathrm{ZnO} \mathrm{NPs}$, the average spreading ratio increases to $72.6 \%$ and $74.4 \%$, respectively. However, upon increasing the NP addition amount to $0.2 \mathrm{wt} . \%$, spreading ratio starts to decrease. Addition of 0.4 wt. $\%$ of $\mathrm{ZnO}$ NPs leads to a spreading ratio of $70.1 \%$.

Addition of $\mathrm{ZnO}$ NPs up to 0.1 wt.\% has improved the wettability of the $\mathrm{Sn} 57 \mathrm{Bi}$ by reducing the surface tension between the molten solder and the $\mathrm{Cu}$ substrate. Generally, capillary forces and the contact angle are considered as the main driving force for the spreading of molten metal towards a curvature shape (Ref 17). The contact angle $(\theta)$ is the balance of the surface energy forces existing between the solid, liquid and the vapor phase as given by the classical Young-Dupre Eq 2: (Ref 18).

$\operatorname{Cos} \theta=\frac{\gamma_{\mathrm{SV}}-\gamma_{\mathrm{SL}}}{\gamma_{\mathrm{LV}}}$

where $\gamma_{S V}$ is the solid-vapor surface energy; $\gamma_{S L}$ is the solidliquid interface surface energy and $\gamma_{L V}$ is the liquid-vapor surface tension. For a good spreading $\operatorname{Cos} \theta$ should be maximum. In reactive spreading, the spread rate is dependent on thermodynamics and kinetics of metallurgical and chemical reaction at the interface. Formation of $\mathrm{Cu}_{6} \mathrm{Sn}_{5}$ IMC during wetting reduces the $\gamma_{\mathrm{SL}}$ term as given by Eq 3: (Ref 18)

$\gamma_{\mathrm{SL}}=\gamma_{\mathrm{SL}}^{0}+\Delta G_{\mathrm{Cu}_{6} \mathrm{Sn}_{5}}$

where $\gamma_{S L}^{0}$ is the solid-liquid interface surface energy before the $\mathrm{Cu}_{6} \mathrm{Sn}_{5}$ formation and $\Delta G_{\mathrm{Cu}_{6} S n_{5}}$ is the Gibbs free energy per

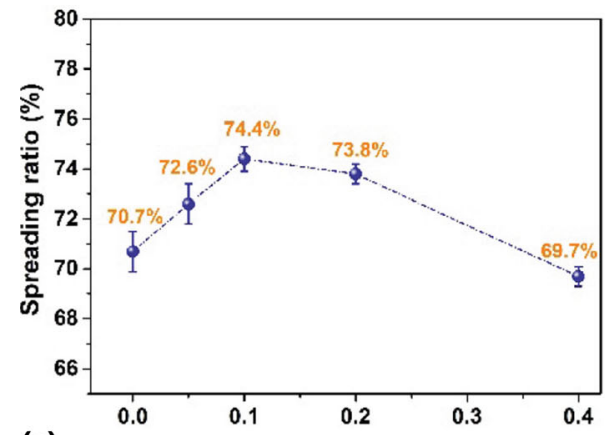

(a)

ZnO nanoparticle addition (weight\%) unit area for the $\mathrm{Cu}_{6} \mathrm{Sn}_{5}$ formation $\left(\Delta G_{C u_{6} S n_{5}}\right.$ is a negative number). As per the theory of adsorption, NPs in the molten solder gets adsorbed at the interface and increase the number of $\mathrm{Cu}_{6} \mathrm{Sn}_{5}$ grains per unit area (Ref 19). In other words, NPs increases the driving force for the nucleation of $\mathrm{Cu}_{6} \mathrm{Sn}_{5}$ phases which eventually lead to the decrease in the surface tension (Ref 20). Besides, upon spreading, ZnO NPs redistributes within the molten solder. At higher addition amount, accumulation of NPs at the leading edge can slow down the capillary flow, thus reducing the spreading ratio as shown schematically in Fig. 3(b).

\subsection{Tensile Properties}

Figure 4(a) shows the room temperature tensile test for monolithic and $\mathrm{ZnO}$ added $\mathrm{Sn} 57 \mathrm{Bi}$ solder. The tensile curves for all the investigated samples have a similar shape where the flow stress reaches a maximum after an elastic deformation, yielding and strain hardening. Afterwhich the flow stress decreases with an increase in strain and finally fractures. Figure 4(b) shows the average values of the ultimate tensile strength (UTS) and \% elongation obtained from the tensile test. As seen from the results, UTS increases linearly with the increasing addition of ZnO NPs. The average UTS increased from $62.3 \mathrm{MPa}$ of the monolithic Sn57Bi to $74.4 \mathrm{MPa}$ (about $19 \%$ increase) for the $0.4 \mathrm{wt} . \% \mathrm{ZnO}$ added solder. Elongation increased from $54.3 \%$ of the monolithic Sn57Bi to $59.2 \%$ for the $0.05 \mathrm{wt} \% \mathrm{ZnO}$ addedSn57Bi alloy. Whereas, for higher addition of $\mathrm{ZnO} \mathrm{NPs}$, elongation shows a decreasing trend. The increase in the tensile properties with the addition $\mathrm{ZnO}$ addition can be attributed to two reasons: (a) dispersion strengthening due to the presence of harder ZnO NPs in the matrix and (b) fine eutectic lamellar spacing between $\mathrm{Sn}$ and $\mathrm{Bi}$ phases. Nanosized $\mathrm{ZnO}$ dispersed in the solder matrix assists in obstructing the dislocation movement thereby increasing the strength of the solder (Ref 14). Also, fine eutectic lamellar spacing increases the $\mathrm{Sn}$ and $\mathrm{Bi}$ phase boundaries and thereby restrict the movement of dislocations (Ref 21). Meanwhile, the presence of $\mathrm{ZnO}$ NPs retards the sliding between $\mathrm{Bi}$ and $\mathrm{Sn}$-rich phases, thereby significantly reducing their ductility. Figure 4(c) and (d) shows the fractured surfaces of Sn57Bi alloy with 0.05 wt. $\%$ and 0.4 wt.\% $\mathrm{ZnO}$ NPs respectively. In general, fracture in eutectic $\mathrm{SnBi}$ alloy balances the toughness of ductile Sn-rich phase and the brittle Bi phase. The bulge fracture occurs in the ductile Sn-rich phase and cleavage fracture occurs in the brittle

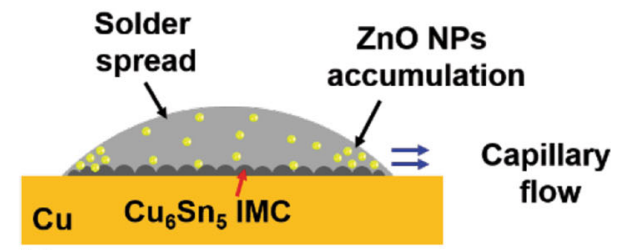

(b)

Figure 3 (a) Spreading ratio of $\mathrm{Sn} 57 \mathrm{Bi}$ solder on cu substrate with varying $\mathrm{ZnO}$ nanoparticle addition, and (b) schematic illustration of accumulation of $\mathrm{ZnO}$ nanoparticle at higher addition amount 

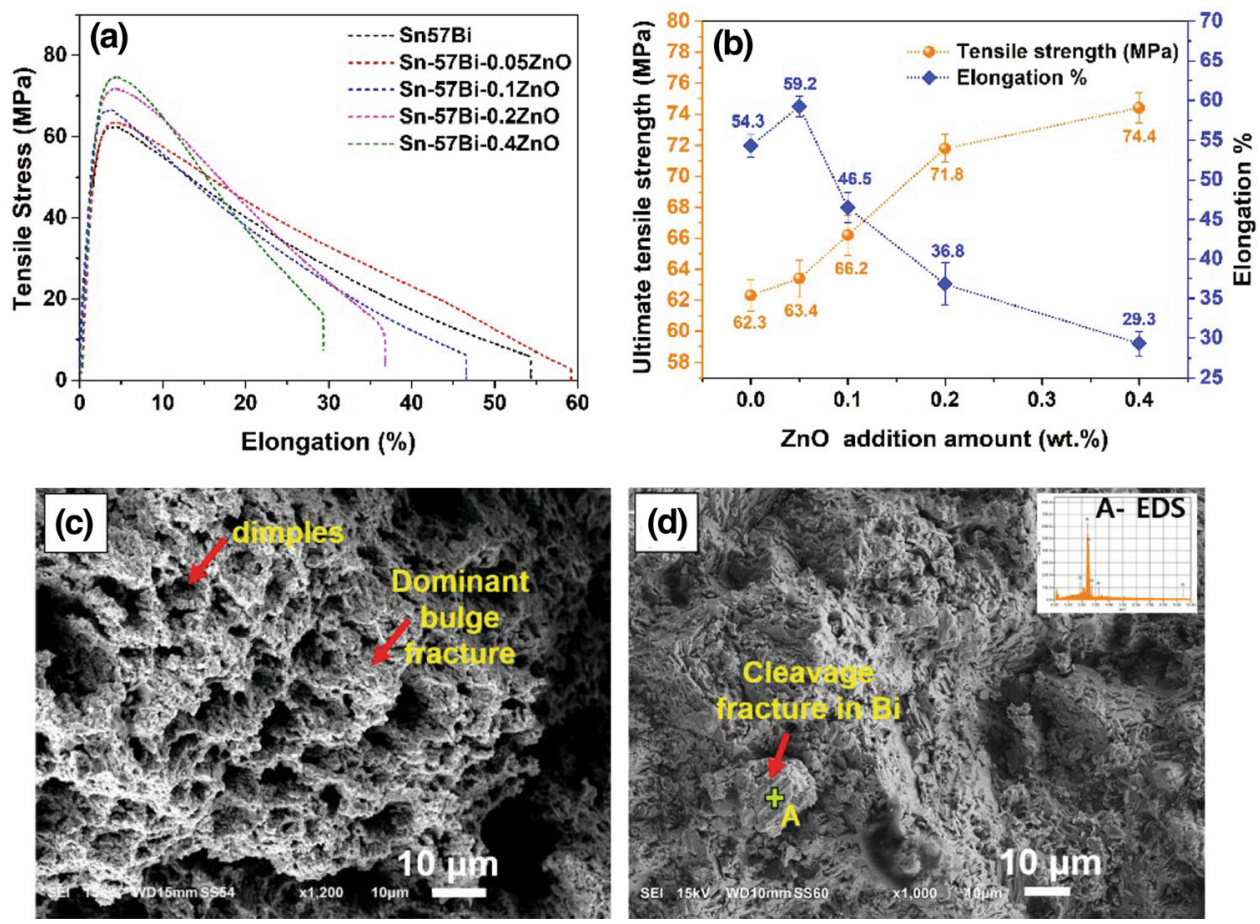

Figure 4 Tensile results of monolithic and $\mathrm{ZnO}$ nanocomposite $\mathrm{Sn} 57 \mathrm{Bi}$ solder, (a) stress-strain curves, (b) tensile properties, (c) and (d) fractured surface of nanocomposite Sn57Bi solder with 0.05 wt.\% and 0.4 wt.\% $\mathrm{ZnO}$ addition, respectively

Bi phase (Ref 22). Sn57Bi alloy with 0.05 wt.\% $\mathrm{ZnO}$ (Figure 4c) shows a dominant bulge fracture mode with dimples. The higher deformation exhibited by the ductile Snrich phase under tensile strain aids the sliding of phase boundaries resulted in the bulge fracture. However, with increasing NPs amount, the ductility decreases and cleavage fracture is observed in $\mathrm{Sn} 57 \mathrm{Bi}-0.4 \mathrm{ZnO}$ alloy as shown in Figure 4(d). EDS analysis (Figure 4(d) insert) shows the cleavage plane corresponding to the brittle $\mathrm{Bi}$ phase. At higher addition, the Sn-rich phase may exhibit lesser deformation under tensile strain, owing to the dispersion hardening of Sn by ZnO NPs. This decreases the ductility of Sn-rich phase. Also, increased NPs interactions could lead to clustering of NPs thereby affecting the sliding of $\mathrm{Sn}$ and $\mathrm{Bi}$ phases.

\section{Conclusion}

In this work, $\mathrm{ZnO}$ nanoparticles were successfully dispersed in the molten $\mathrm{Sn}-\mathrm{Bi}$ solder using a liquid-state ultrasonic treatment. The influence of $\mathrm{ZnO}$ NPs on the microstructure, wettability and mechanical properties of $\mathrm{Sn} 57 \mathrm{Bi}$ solder are analyzed. The results are as follows:

1. The microstructure of Sn57Bi solder alloy is refined with increasing the addition of $\mathrm{ZnO}$ NPs. The average eutectic spacing decreases to a minimum value of $1.4 \pm 0.5 \mu \mathrm{m}$ after the addition of 0.2 wt.\% $\mathrm{ZnO}$ NPs. However, beyond 0.3 wt. $\% \mathrm{ZnO}$ addition, the eutectic spacing begins to coarsen.

2. Spreading tests revealed that addition of $\mathrm{ZnO}$ NPs up to 0.2 wt. $\%$ has improved the spreading ratio of Sn57Bi sol- der. However, higher addition amounts degraded the spreading ratio.

3. The mechanical testing revealed that tensile strength of the Sn57Bi matrix can be improved with the increasing amount of $\mathrm{ZnO}$ NPs. The tensile strength increases to a maximum value of $74.4 \mathrm{MPa}$ for $0.4 \mathrm{wt} \%$ addition which corresponds to about $19 \%$ increase from monolithic Sn57Bi solder.

4. Addition of 0.05 wt. $\%$ of $\mathrm{ZnO}$ NPs leads to $9 \%$ increase in elongation without loss in tensile strength. However, ductility of the composite solders was found to decrease with the increase in $\mathrm{ZnO}$ NPs addition. Correspondingly, the fracture mode of the $\mathrm{Sn} 57 \mathrm{Bi}-0.05 \mathrm{ZnO}$ solder was mostly ductile bulge mode, whereas that of Sn57Bi-0.4 $\mathrm{ZnO}$ solder was brittle with a cleavage plane.

\section{Funding}

This work was supported by the National Research Foundation of Korea (NRF) Grant funded by the Korea government (MEST) (No. NRF-2020R1A2C1009851).

\section{References}

1. Y. Zhong, Y.R. An, H. Ma, and C. Wang, Low-Temperature-Solderable Intermetallic Nanoparticles for 3D Printable Flexible Electronics, Acta Mater., 2019, 162, p 163-175

2. M.S. Kim, Y.H. Ko, S. Yoo, and C.W. Lee, Mechanical Properties of Sn-Bi Bumps on Flexible Substrsate, 2013 IEEE 63rd Electronic Components and Technology Conference, Las Vegas, NV, 2013, pp. 971-975 
3. F. Wang, H. Chen, Y. Huang, Liu L, and Zhang Z, Recent Progress on the Development of Sn-Bi Based Low-Temperature Pb-Free Solders, $J$. Mater. Sci. Mater. Electron., 2019, 30, p 3222-3243

4. L. Yang, L. Zhu, Y. Zhang, P. Liu, N. Zhang, S. Zhou, and L. Jiang, Microstructure and Reliability of Mo Nanoparticle Reinforced Sn58Bi-Based Lead-Free Solder Joints, Mater. Sci. Technol., 2017, 34(8), p 992-1002

5. L. Yang, J. Dai, Y. Zhang, Y. Jing, J. Ge, and H. Liu, Influence of $\mathrm{BaTiO}_{3}$ Nanoparticle Addition on Microstructure and Mechanical Properties of Sn-58Bi Solder, J. Electron Mater., 2015, 44(7), p 2473 2478

6. T.W. Hu, Y. Li, Y.C. Chan et al., Effect of nano $\mathrm{Al}_{2} \mathrm{O}_{3}$ Particles Doping on Electro Migration and Mechanical Properties of Sn-58Bi Solder Joints, Microelectron. Reliab., 2015, 55(8), p 1226-1233

7. X. Li, Y. Ma, W. Zhou et al., Effects of nanoscale $\mathrm{Cu}_{6} \mathrm{Sn}_{5}$ Particles Addition on Microstructure and Properties of SnBis Solder Alloys, Mater. Sci. Eng. A, 2017, 684, p 328-334

8. N. Wu, S. Ismathullakhan, and Y.C. Cha, Effect of 1 wt.\% $\mathrm{ZnO}$ Nanoparticles Addition on the Microstructure, IMC Development, and Mechanical Properties of High Bi Content Sn-57.6Bi-0.4Ag Solder on Ni Metalized Cu Pads, J. Mater. Sci. Mater. Electron., 2014, 25, p 2169-2176

9. L.Y. Chen, J.Y. Peng, J.Q. Xu, H. Choi, and X.C. Li, Achieving Uniform Distribution and Dispersion of a High Percentage of Nanoparticles in Metal Matrix Nanocomposites by Solidification Processing, Scr. Mater, 2013, 69(8), p 634-637

10. T. Paul, C. Zhang, B. Boesl, and A. Agarwal, Analytical Review of Reinforcement Addition Techniques During Ultrasonic Casting of Metals Matrix Composites, Adv. Eng. Mater., 2020, 22, p 1-19

11. D.G. Eskin, I. Tzanakis, F. Wang, G.S.B. Lebon, T. Subroto, K. Pericleous, and J. Mi, Fundamental Studies of Ultrasonic Melt Processing, Ultrason Sonochem., 2019, 52, p 455-467

12. R.S. Harini, J. Nampoothiri, B. Nagasivamuni, B. Raj, and K.R. Ravi, Ultrasonic Assisted Grain Refinement of Al-Mg Alloy Using in-situ $\mathrm{MgAl}_{2} \mathrm{O}_{4}$ Particles, Mater. Lett., 2015, 145, p 328-331

13. I. Tzanakis, W.W. Xu, D.G. Eskin, P.D. Lee, and N. Kotsovinos, In situ Observation and Analysis of Ultrasonic Capillary Effect in Molten Aluminium, Ultrason. Sonochem., 2015, 27, p 72-80
14. D.H. Jung, A. Sharma, D.U. Lim, J.H. Yun, and J.P. Jung, Effects of AlN Nanoparticles on the Microstructure, Solderability, and Mechanical Properties of Sn-Ag-Cu solder, Metall. Mater. Trans. A, 2017, 48, p 4372-4384

15. L. Yang, C. Du, J. Dai, N. Zhang, and Y. Jing, Effect of Nanosized Graphite on Properties of Sn-Bi Solder, J. Mater. Sci. Mater. Electron., 2013, 24, p 4180-4185

16. T. Matsunaga, K. Ogata, T. Hatayama, K. Shinozaki, and M. Yoshida, Effect of Acoustic Cavitation on Ease of Infiltration of Molten Aluminum Alloys into Carbon Fiber Bundles Using Ultrasonic Infiltration Method, Compos. A, 2007, 38, p 771-778

17. J. Liang, N. Dariavach, P. Callahan, and D. Shangguan, Metallurgy and Kinetics of Liquid-Solid Interfacial Reaction During Lead-Free Soldering, Mater. Trans., 2006, 47(2), p 317-325

18. L. Yin, B.T. Murray, S. Su, Y. Sun, Y. Efraim, H. Taitelbaum, and T.J. Singler, Reactive Wetting in Metal-Metal System, J. Condens. Matter Phys., 2009, 21(46), p 1-11

19. A.T. Tan, A.W. Tan, and F. Yusof, Influence of Nanoparticle Addition on the Formation and Growth of Intermetallic Compound (IMCs) in $\mathrm{Cu} / \mathrm{Cu}-\mathrm{Sn}-\mathrm{Ag} / \mathrm{Cu}$ Solder Joint During Different Thermal Condition, Sci. Technol. Adv. Mater, 2015, 16(3), p 033505

20. R.A. Gagliano, G. Ghosh, and M.E. Fine, Nucleation Kinetics of $\mathrm{Cu}_{6} \mathrm{Sn}_{5}$ by Reaction of Molten tin with a Copper Substrate, J. Electron. Mater, 2002, 31(11), p 1195-1202

21. B.L. Silva, M.G.C. Xavier, A. Garcia, and J.E. Spinelli, $\mathrm{Cu}$ and Ag Additions Affecting the Solidification Microstructure and Tensile Properties of Sn-Bi Lead-Free Solder Alloys, Mater. Sci. Eng. A, 2017, 705, p 325-334

22. C.H. Yang, S. Zhou, S.K. Lin, and H. Nishikawa, A Computational Thermodynamics-Assisted Development of Sn-Bi-In-Ga Quaternary Alloys as Low-Temperature Pb-Free Solders, Materials, 2019, 12(4), p $1-16$

Publisher's Note Springer Nature remains neutral with regard to jurisdictional claims in published maps and institutional affiliations. 